\title{
MELHORIA DE QUALIDADE DO AÇO ELÉTRICO LIGADO AO SILÍCIO ATRAVÉS DA LAMINAÇÃO EM FASE FERRÍTICA NA LINHA DE TIRAS A QUENTE*
}

Jonatas Venâncio Barbosa ${ }^{1}$ Edmilson Fernandes Dadomi Priscila Batista Dias ${ }^{3}$

\section{Resumo}

Descrevem-se as ações adotadas para a evolução da qualidade de aços ultra baixo carbono com alto teor de silício, destinados a aplicações eletrônicas. Com o propósito de conhecer o comportamento metalúrgico do material durante o processo de laminação foram realizados ensaios de dilatometria, que permitiram a determinação das temperaturas de transformação de fase. Foi evidenciado que, nas temperaturas de processo praticadas, a laminação no trem acabador ocorria na região intercrítica, gerando variações bruscas de propriedades mecânicas no processo, levando a instabilidade operacional. Esta condição de laminação foi corrigida, direcionando para laminação em fase ferrítica. Foram necessários ajustes no modo de operação na linha de tiras a quente e a criação de controle automático de temperatura na entrada do trem acabador. Após as ações foi possível melhorar a qualidade do produto final, em relação às dimensões e forma do produto, reduzindo as perdas internas e retrabalho.

Palavras-chave: Laminação em fase ferrítica; Aço elétrico; Transformações de fase; Tensão entre cadeiras.

\section{QUALITY IMPROVEMENT IN ELECTRIC SILICON STEELS THROUGH FERRITIC ROLLING IN THE HOT STRIP MILL}

\begin{abstract}
It is described the actions performed to quality improvement of ultra low carbon steels with high silicon content, designated to electronic application. With the purpose of understanding the metallurgical behavior of the material in the rolling process, dilatometry analyses were performed, allowing determination of phase transformation temperatures. Therefore it was shown that the rolling process in the finish mill was taking place at intercritical temperature region causing abrupt variation in mechanical properties, leading to operational instability. This rolling condition was revised, redirecting towards rolling in ferritic phase. It was necessary adjustments in the operational mode in the hot strip mill line, and the creation of an automatic temperature control in the entry of the finishing mill. With these actions it was accomplished diminution of internal material loss and rework.

Keywords: Ferritic rolling; Electric steels; Phase transformation; Tension between stands.

1 Engenheiro Metalurgista, CQE/ASQ, Gerência Técnica de Laminação a Quente da Usiminas, Ipatinga, MG.

2 Engenheiro de Produção, Laminação de Tiras a Quente da Usiminas, Ipatinga, MG.

3 Engenheiro Metalurgista, Centro de Tecnologia Usiminas, Ipatinga, MG.
\end{abstract}




\section{INTRODUÇÃO}

Uma importante etapa da laminação de tiras a quente é o processamento do aço no laminador acabador, responsável por prover aos produtos finais a dimensão, a forma em geral, o aspecto superficial e as propriedades mecânicas. Para obtenção de tais requisitos o laminador é controlado por um modelo matemático de setup, e um controle dinâmico de forma, espessura, temperatura e do fluxo de massa entre cadeiras. Os controles são dependentes da capacidade de previsão da resistência à deformação dos materiais. Entretanto os controles/atuadores do processo podem não ser eficazes quando há mudanças repentinas nas características mecânicas do material durante o processo no trem acabador. Um dos exemplos deste tipo de fenômeno ocorre quando o material apresenta transformação de fases dentro do laminador.

Desta forma a qualidade do processo de laminação a quente passa pelo conhecimento dos fundamentos metalúrgicos que envolvem os aços, especialmente as temperaturas de transformação de fases de austenita $(g)$ para ferrita $(\alpha)$ durante a laminação. Usualmente as temperaturas de acabamento são direcionadas para garantir uma laminação fora da região intercrítica. Entretanto existem exceções, como são os casos de aços elétricos produzidos na USIMINAS.

O aço elétrico de grão não orientado semiprocessado (GNO-SP) possui importante papel comercial, com aplicação eletromagnética em núcleos de pequenos motores industriais, aparelhos domésticos, transformadores e compressores herméticos para refrigeração. Esses aços são produzidos na condição de ultra baixo carbono, e são fabricados com adições de elementos como silício e alumínio.

Durante o processo de fabricação deste aço na laminação de tiras a quente foram observados casos de instabilidade entre cadeiras, com variações de tensão, afetando a largura e a espessura deste aço, com elevado índice de retrabalho. No estudo da causa raiz foi observado que estes defeitos estavam associados à transformação de fases dentro do trem acabador, perturbando o correto controle do fluxo de massa entre cadeiras, dentre outras dificuldades. Tais dificuldades de processo motivaram o presente estudo.

No estudo realizado por Equihua [1], foi avaliada a influência dos elementos Si e Al na temperatura de transformação de fase em um aço elétrico baixo carbono, constatando que a adição destes elementos eleva as temperaturas de início de transformação de fases. Marra [2] estudou o comportamento mecânico-metalúrgico durante a laminação de acabamento de um aço elétrico ultra baixo carbono, com adições de silício, alumínio e manganês, sendo identificado que o material era parcialmente laminado na região ferrítica.

Foi observada a oportunidade de laminação totalmente na fase ferrítica de um aço elétrico produzido na USIMINAS, com composição química próxima das referências citadas [1] e [2], com o objetivo de melhoria da qualidade final do produto, e maior estabilidade do processo, principalmente em vista as dificuldades encontradas do controle do fluxo de massa deste material durante as ocorrências de transformação de fase na laminação de acabamento.

Sendo assim este trabalho foi separado em duas etapas: (i) Identificação do comportamento metalúrgico do aço elétrico em questão durante a laminação a quente, principalmente a identificação das temperaturas alotrópicas de transformação de fases e (ii) adequação do processo industrial para obtenção de uma laminação totalmente em fase ferrítica destes materiais no trem acabador. 


\section{MATERIAIS E MÉTODOS}

A linha de Tiras a Quente da Usina de Ipatinga possui três fornos de reaquecimento, duas descarepações individualizadas, dois laminadores desbastadores com descarepações de entrada e saída, uma tesoura de pontas (Crop-Shear), seis cadeiras de acabamento e duas bobinadeiras, conforme Figura 1.

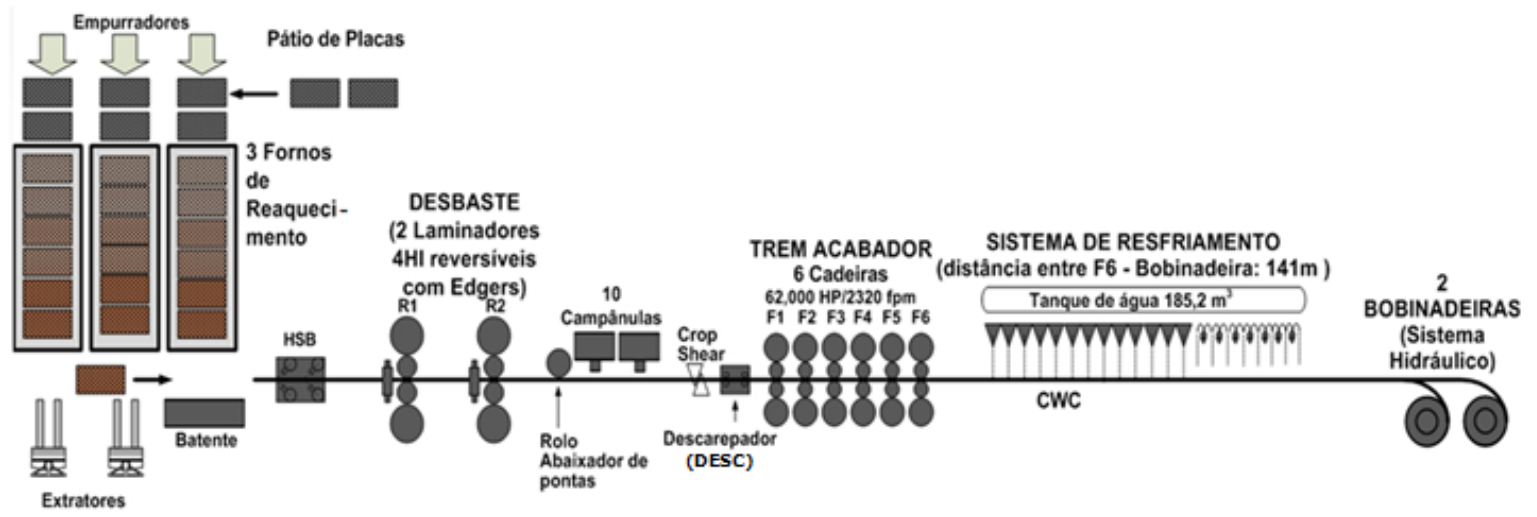

Figura 1. Linha de Tiras a Quente da Usina de Ipatinga.

O estudo foi realizado em um aço elétrico USICORE230 de grão não orientado semiprocessado (GNO-SP) de composição química conforme demonstrada na Tabela 1.

Tabela 1. Composição Química do Aço Elétrico USICORE230 [\% em peso] [3]

\begin{tabular}{cccccc}
\hline $\mathbf{C}$ & $\mathbf{A l}$ & $\mathbf{S i}$ & $\mathbf{M n}$ & $\mathbf{S}$ & $\mathbf{P}$ \\
\hline 0,10 máx. & 0,30 mín. & 1,50 máx. & 0,70 máx. & 0,020 máx. & 0,040 máx. \\
\hline
\end{tabular}

$\mathrm{Na}$ primeira etapa do estudo, a de caracterização das temperaturas de transformação de fase, foi retirada uma amostra na ponta inicial do esboço após a laminação de desbaste e corte de pontas na tesoura (Crop-Shear) com posterior resfriamento ao ar. As espessuras do esboço e da bobina a quente são de $24 \mathrm{~mm}$ e $2,5 \mathrm{~mm}$, respectivamente.

Foram determinadas as temperaturas de transformação de fase $\mathrm{Ar}_{3}$ e $\mathrm{Ar}_{1}$ mediante ensaios dilatométricos com deformação, onde o aço foi submetido a ciclos termomecânicos utilizando o módulo de compressão no dilatômetro de deformação DIL850 A/D. Os corpos-de-prova analisados foram retirados a $1 / 4$ da espessura do esboço, com comprimento de $10 \mathrm{~mm}$ e diâmetro de $5 \mathrm{~mm}$.

A taxa de resfriamento utilizada foi de $15^{\circ} \mathrm{C} / \mathrm{s}$, com deformação verdadeira de 0,2 a uma taxa de deformação de $10 \mathrm{~s}^{-1}$. As temperaturas de ensaio foram definidas procurando-se abranger as temperaturas do processo industrial desde o final do desbaste até o acabamento final.

Em uma segunda etapa, uma vez caracterizada as temperaturas $\mathrm{Ar}_{3}$ e $\mathrm{Ar}_{1}$, optou-se por realizar uma laminação experimental totalmente em fase ferrítica, sendo necessário adequar o modo de operação da linha de tiras a quente para obtenção das temperaturas visadas de processo. Para tal, houve a necessidade de controlar a temperatura máxima de entrada no laminador acabador, garantindo assim a laminação fora da região intercrítica. 
Foi então desenvolvida uma lógica de controle automático de temperatura na entrada do laminador acabador. Este controle permite ajustar a temperatura de entrada no trem acabador sem perda de produtividade na linha. No caso de excesso de temperatura de entrada no laminador acabador, baseado na temperatura medida no pirômetro de entrada $\left(T_{s}\right)$, o esboço passa a oscilar automaticamente até atingir a temperatura ideal de processo. Desta forma o sistema bloqueia eventuais erros de controle de temperatura na linha. Um esquema da lógica é demonstrado na Figura 2.

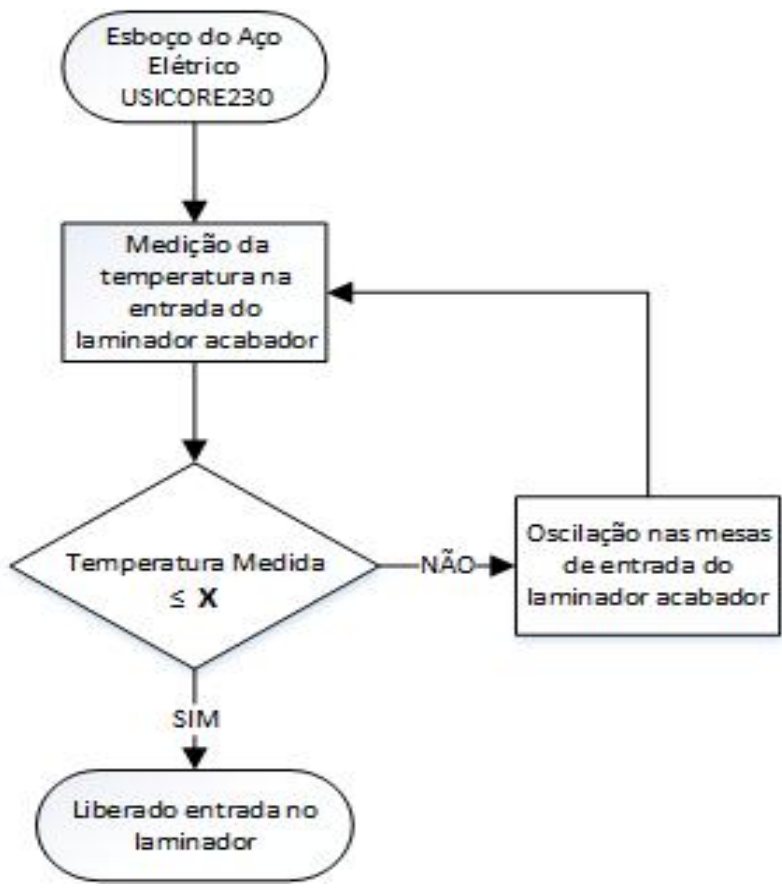

Figura 2. Lógica do controle automático de temperatura na entrada do laminador acabador.

Adicionalmente foram realizadas ações para adequar a temperatura de chegada do esboço na entrada do laminador acabador, para obtenção de uma temperatura de acordo com a visada, e obtenção de um perfil térmico ao longo do comprimento mais uniforme possível. Sendo elas:

- Aumentou-se o número de descarepações ao longo de todo o comprimento do esboço nos desbastadores;

- Elaborou-se um controle automático da velocidade de laminação nos desbastadores.

\section{RESULTADOS E DISCUSSÃO}

A variação da tensão média de fluxo em função da temperatura de deformação é exibida na Figura 3. Por este resultado podem ser identificadas três regiões distintas. A primeira região (I), de domínio austenítico, corresponde a deformações em altas temperaturas, onde a tensão de fluxo cresce à medida que a temperatura cai. A segunda região da curva (II), correspondente à transformação parcial de austenita $\rightarrow$ ferrita, é caracterizada pela queda na tensão de fluxo à medida que a temperatura cai também chamada de região intercrítica. Na terceira e última região (III), onde a transformação austenita $\rightarrow$ ferrita foi finalizada, a tensão novamente cresce à medida que a temperatura cai. Conforme Yue e Jonas [4], as temperaturas de transformação, $A r_{3}$ e $A r_{1}$, são determinadas aproximadamente em pontos de 
inflexão neste tipo de curva, ou na interseção das zonas I e II para $\mathrm{Ar}_{3}$, e no ponto mínimo da parábola correspondente às regiões II e III para Ar1.

Com isto pôde-se estimar as temperaturas críticas do aço, com $\mathrm{Ar}_{3}$ em $1000^{\circ} \mathrm{C}$ e $\mathrm{Ar}_{1}$ em $925^{\circ} \mathrm{C}$. As elevadas temperaturas de transformação obtidas confirmaram a influência do silício e do alumínio [1] e [2], além do baixo teor de carbono [5], no seu aumento.

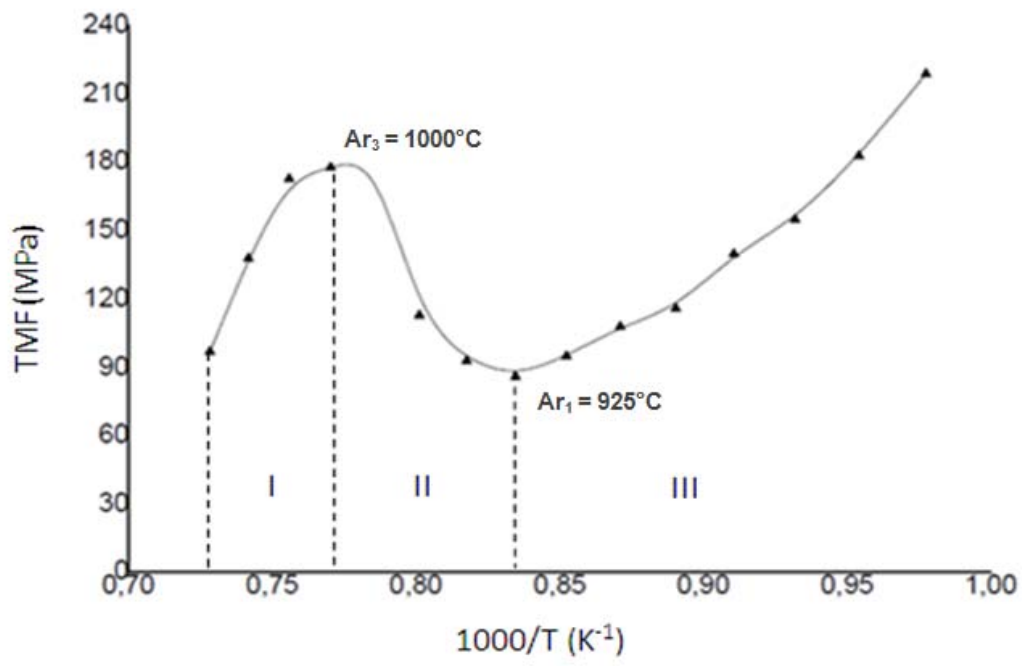

Figura 3. Tensão média de fluxo a varias temperaturas para o aço elétrico USICORE230.

Pelo resultado da tensão média de fluxo (TMF), a região intercrítica (II) do aço elétrico analisado, entre $\mathrm{Ar}_{3}$ e Ar1, apresenta variação de $100 \mathrm{MPa}$. Pequenas diferenças na temperatura nos materiais no domínio dessa região geram mudanças repentinas na tensão de escoamento do material.

As temperaturas de laminação calculadas pelo modelo matemático de setup do trem acabador a partir da temperatura de entrada medida antes da descarepação são exibidas na Figura 4. A temperatura média de entrada $T_{s}$ obtida nestes materiais era de $984{ }^{\circ} \mathrm{C}$.

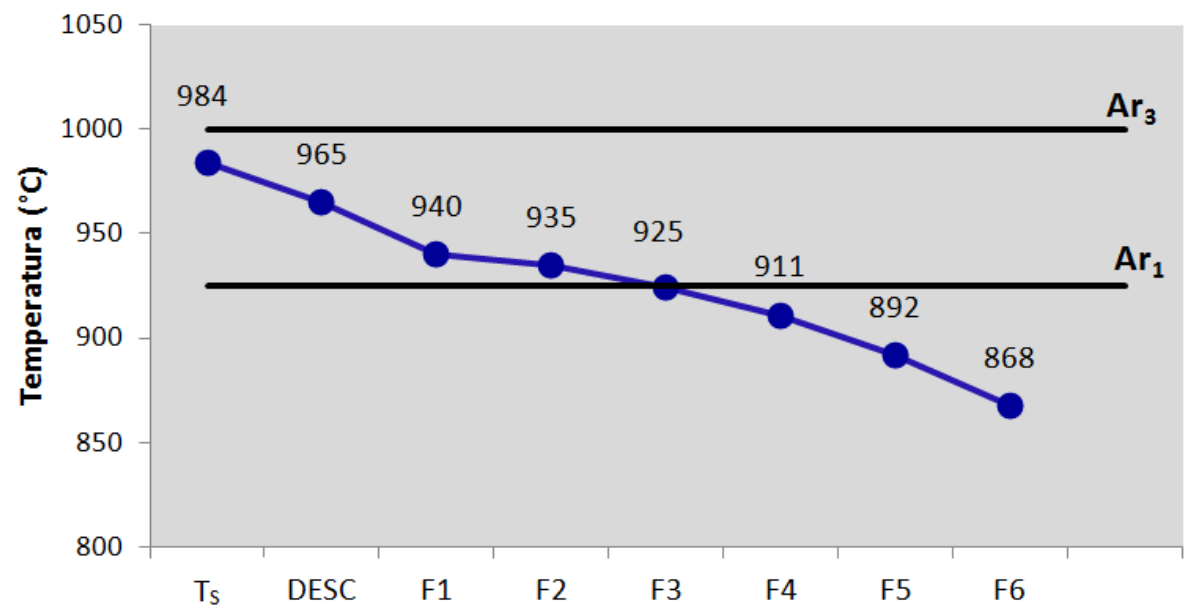

Figura 4. Temperaturas médias de processo no trem acabador do aço elétrico USICORE230 em relação às temperaturas obtidas de transformação de fases.

Observa-se que as temperaturas médias de processo nas cadeiras F1 e F2 estão na região intercrítica, podendo variar em função da temperatura de entrada do esboço 
no trem acabador, Figura 4. Foram identificados casos de bobinas processadas até na cadeira F5 do laminador na região intercrítica. Portanto foi constatado que as temperaturas de processo praticadas para o aço elétrico estudado geravam uma laminação na região intercrítica. Confirmando resultados obtidos por Marra [2] em aços produzidos pela USIMINAS com composição química similar a deste estudo. De acordo com os resultados obtidos, nesta região ocorre uma elevada variação de tensão média de fluxo. A recalescência que acompanha esta reação tende a acentuar as instabilidades de processo [5].

As temperaturas de processamento praticadas geravam uma laminação com ocorrência de transformação de fases dentro do trem acabador, causando as instabilidades relatadas, sabendo-se que variações na temperatura de laminação, associadas a marcas de skid, por exemplo, também geravam variações bruscas na tensão de escoamento. E estas variações na tensão de escoamento levavam a instabilidade no controle de fluxo de massa, gerando distensões entre cadeiras, afetando a estabilidade operacional com consequente falta de largura, erro de planicidade e espessura.

$\mathrm{Na}$ segunda etapa do estudo foi necessário ajustar as temperaturas de processo visando uma laminação em fase ferrítica. A temperatura visada de entrada no trem acabador ( $T_{\mathrm{s}}$ ) passou de $990^{\circ} \mathrm{C}$ para $960^{\circ} \mathrm{C}$. A obtenção deste novo valor visado apresentou algumas dificuldades/desafios.

Primeiro, o controle vigente de temperatura se mostrou ineficaz, com vários casos de excesso de temperatura, gerando instabilidades no material. Foi então criado um bloqueio automático de temperatura máxima de entrada no trem acabador, conforme já mencionado. Este bloqueio mostrou excelentes resultados, resolvendo instantaneamente o problema de elevadas temperaturas, como demonstra a Figura 5. Para melhoria dos resultados, e diminuição do tempo de oscilação dos esboços, foi aumentado o número de descarepações nos dois laminadores desbastadores, e também criado um controle automático de temperatura de entrada no trem acabador, ajustando as velocidades de laminação no desbaste. Estas ações em conjunto permitiram o controle de temperatura de entrada no laminador acabador sem impactar a produtividade do processo.

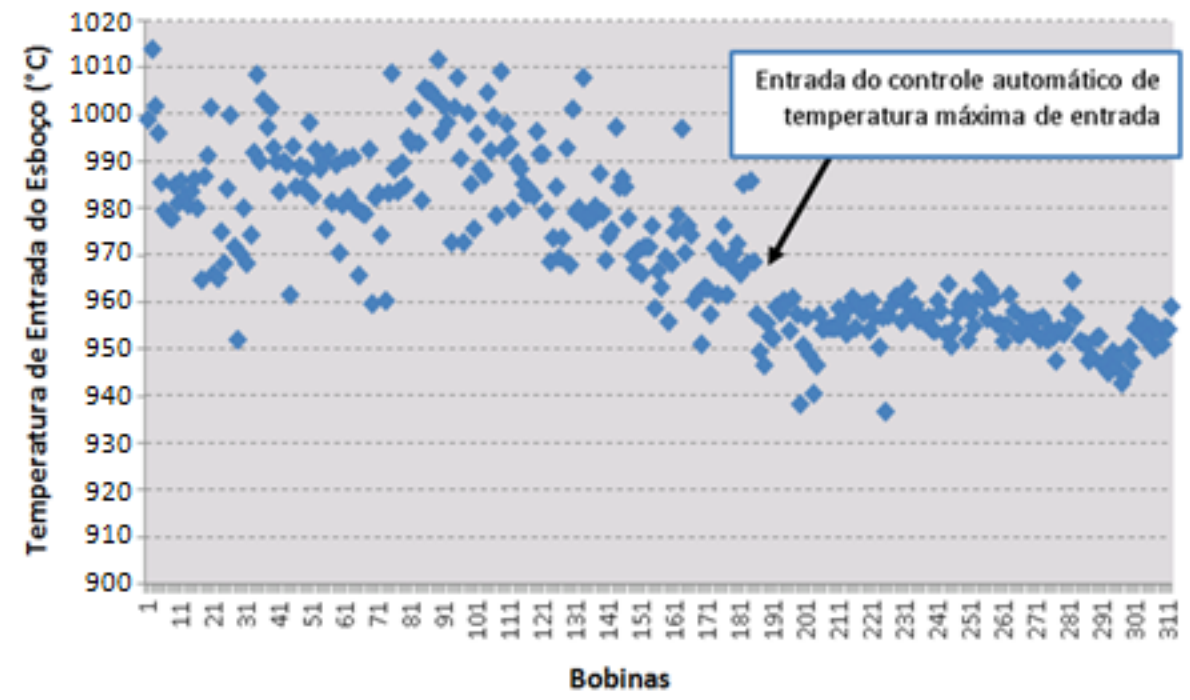

Figura 5. Ativação do controle automático de temperatura máxima de entrada no trem acabador para o aço elétrico USICORE230 e seu impacto na temperatura de entrada. 
Outro aspecto fundamental de controle para uma laminação totalmente em fase ferrítica é o perfil da temperatura do esboço ao longo do comprimento. Perfis térmicos com marcas de skid elevadas ou variação repentina de temperatura afetam os resultados. Faz-se necessário um forno com condições térmicas adequadas que proporcione placas com perfil de temperatura e marcas de skid de acordo com os requisitos de qualidade, além de descarepações no desbaste sem intervenções manuais.

Após alguns testes foi modificada em caráter permanente a temperatura padrão de processo do aço elétrico USICORE230. A média obtida de temperatura de entrada $\mathrm{T}_{\mathrm{s}}$ foi de $952^{\circ} \mathrm{C}$, conforme Figura 6 . Todas as temperaturas médias de processo nas cadeiras do trem acabador passaram a estar abaixo da região intercrítica. Lembrando que foi estabelecida uma temperatura máxima de entrada no topo em função da temperatura $A r_{1}$ determinada, sendo que a dispersão de temperaturas obtidas está abaixo deste valor, garantindo assim a laminação ferrítica em todos os casos.

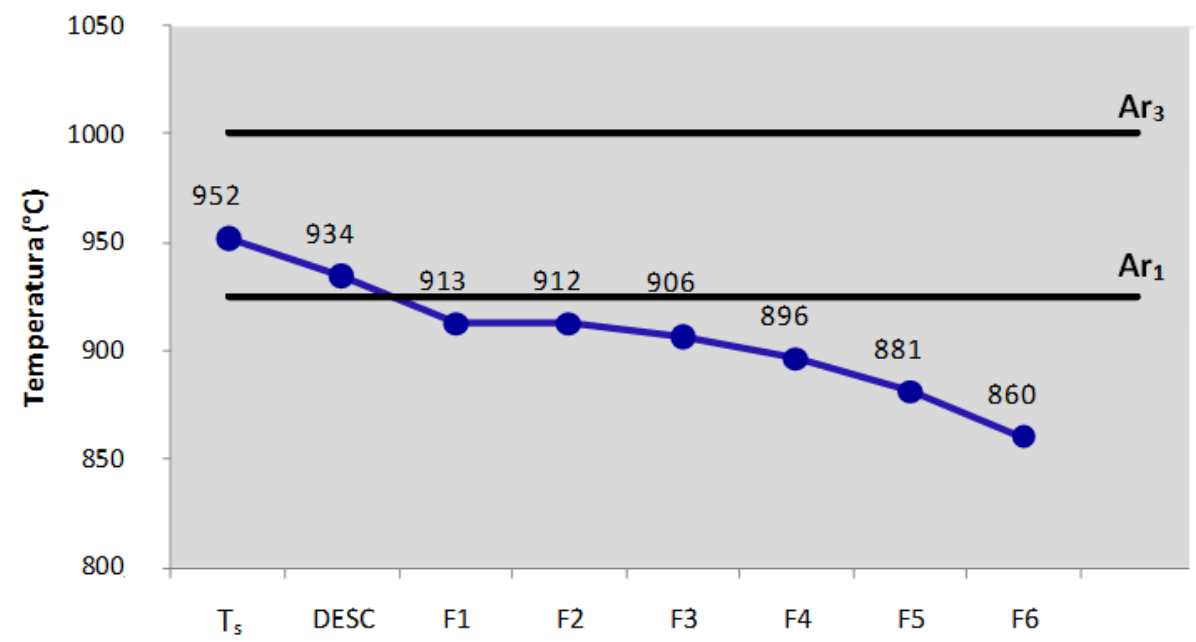

Figura 6. Temperaturas médias de processo no trem acabador do aço elétrico USICORE230 em relação às temperaturas obtidas de transformação de fases após a modificação na temperatura de entrada.

Houve uma leve diminuição da temperatura de acabamento obtida nestes aços, em média $10^{\circ} \mathrm{C}$ menor que a condição anterior. Os resultados de temperatura de acabamento obtidos em relação aos anteriores à modificação são evidenciados na Figura 7. Contudo também foram observadas que as variações nas temperaturas do processo na laminação a quente não afetaram as propriedades elétricas finais do material, e a resistência à deformação durante a relaminação a frio, confirmando os resultados de literatura [5]. Observa-se também que a menor dispersão da temperatura de entrada resultou também em uma menor dispersão de temperatura de acabamento obtida. 
Temperatura de Acabamento

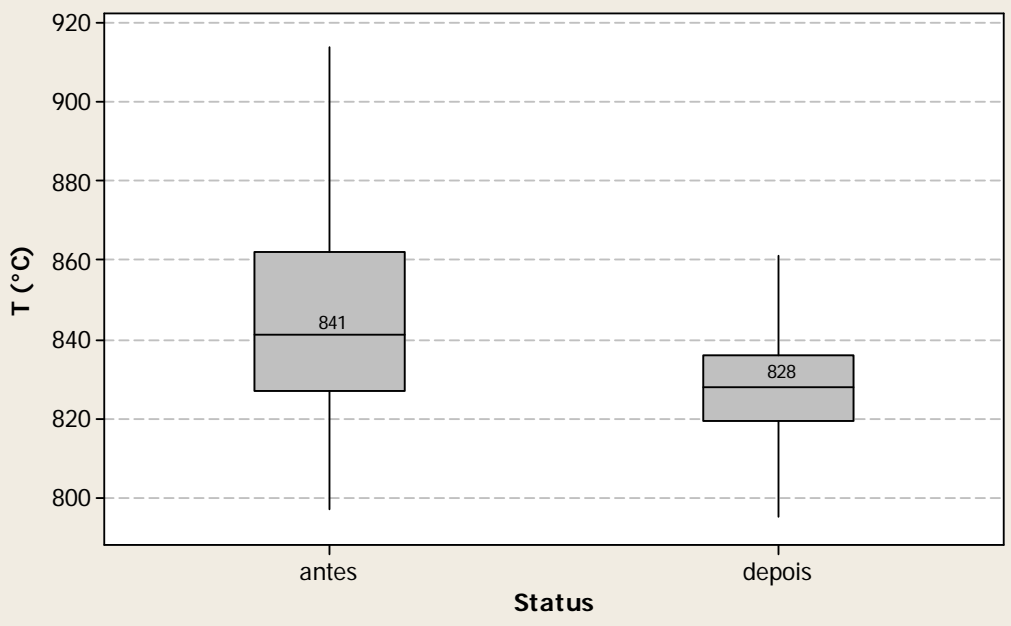

Figura 7. Temperaturas médias de acabamento obtidas na saída do trem acabador no aço elétrico USICORE230 antes e depois da modificação nas temperaturas de processo.

Após vários acompanhamentos na linha, foi criado o padrão de operação para laminação deste material, com cuidados específicos visando à obtenção das temperaturas adequadas de processo.

As novas condições de processamento do aço elétrico USICORE230, proporcionaram benefícios na estabilidade operacional e resultados positivos na qualidade do produto listados abaixo:

i) Diminuição dos descartes por falta de largura

Os descartes por falta de largura no produto final apresentaram queda a partir do momento em que foram realizados os ajustes na temperatura de entrada do trem acabador. A evolução nos descartes desde 2011, antes e após a laminação em fase ferrítica é demonstrada na Figura 8. Observa-se uma redução significativa nos descartes.

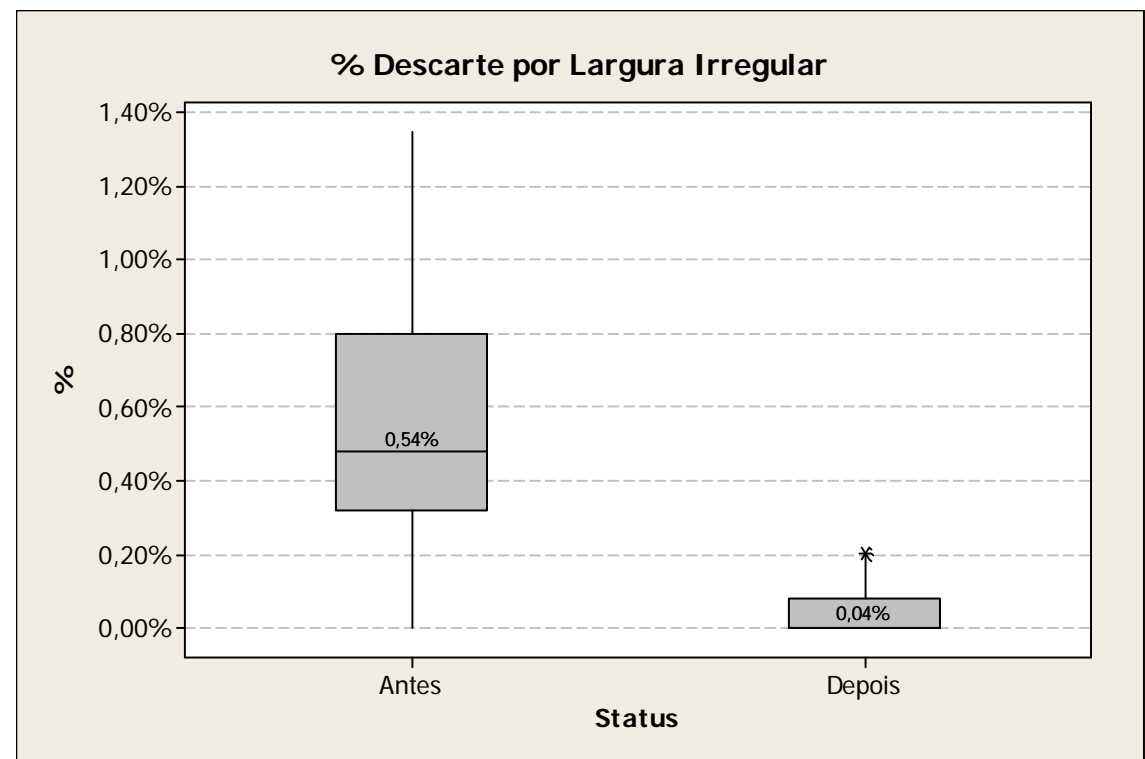

Figura 8. Descartes por falta de largura em aço elétrico USICORE230. 
ii) Melhoria no acerto de espessura

Com a laminação fora da região intercrítica e menor dispersão da temperatura de entrada, ocorreu diminuição da variação de tensão de escoamento durante a laminação. Desta forma, o modelo matemático do trem acabador passou a realizar uma melhor previsão/adaptação dos parâmetros de setup para este aço, aumentando o acerto de espessura no topo das bobinas obtidas conforme Figura 9.

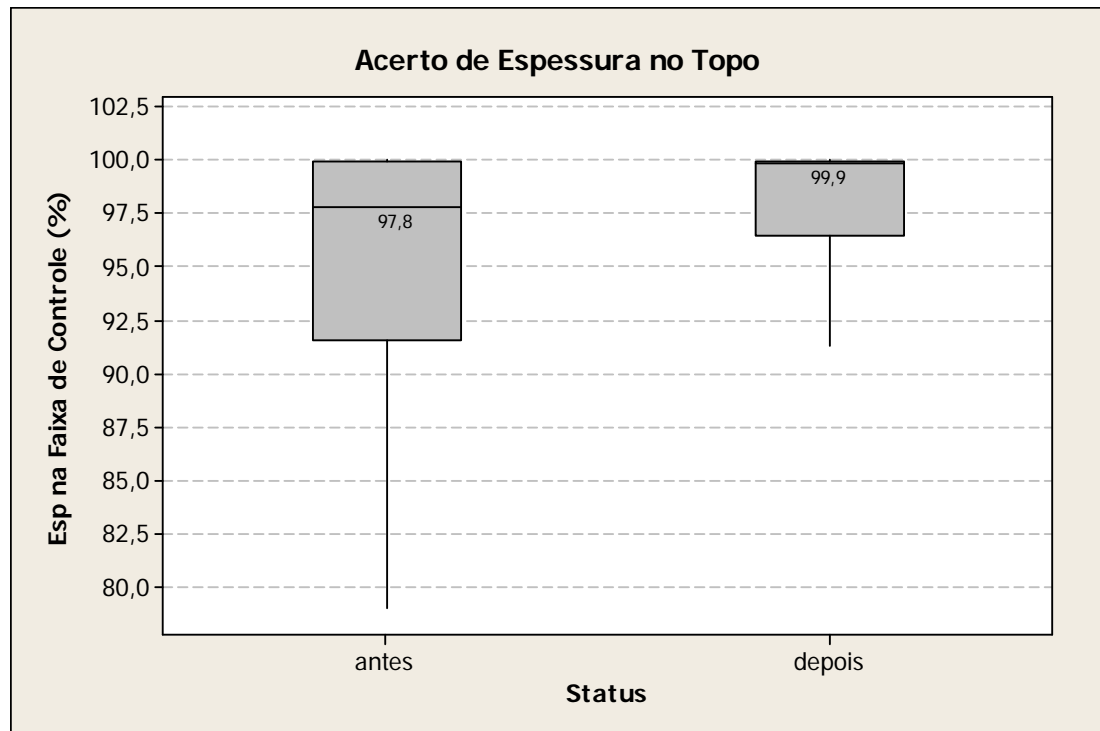

Figura 9. Acerto de espessura nos 20 metros iniciais da tira, no aço elétrico USICORE230 antes da modificação, em laminação convencional, e depois, em laminação em fase ferrítica.

\section{CONCLUSÃO}

Foi realizado ensaio por dilatometria e identificado que a temperatura de transformação de fase de um aço elétrico ultra baixo carbono, com adição de silício, tem início aproximado a $1000^{\circ} \mathrm{C}\left(\mathrm{Ar}_{3}\right)$ e final a $925^{\circ} \mathrm{C}\left(\mathrm{Ar}_{1}\right)$. Esta simulação evidenciou que a temperatura de entrada visada no trem acabador praticada anteriormente levava a uma variação brusca na tensão de escoamento do material dentro do laminador, provocando instabilidades de controle e erro de cálculos do setup do modelo matemático.

Baseado nas temperaturas alotrópicas de transformação de fase caracterizadas pela simulação foi alterado a temperatura visada de entrada no trem acabador de $990^{\circ} \mathrm{C}$ para $960^{\circ} \mathrm{C}$. Para atingir o novo patamar de temperatura foi necessário elaborar um controle automático da temperatura máxima de entrada no trem acabador, e realizar ajustes no modo de operação na linha de tiras a quente.

Com estas ações foi possível a laminação em escala industrial do aço elétrico em fase ferrítica em todas as cadeiras do laminador, sem prejudicar a produtividade, obtendo melhoria da qualidade dos produtos obtidos e com maior estabilidade do processo.

\section{Agradecimentos}

Os autores agradecem todo o apoio da equipe da operação da linha de tiras a quente da Usiminas Ipatinga, a Ronaldo Augusto Rebelo pelos ajustes nas lógicas de controle e a José de Pádua Ferreira pelo apoio técnico em geral. 


\section{REFERÊNCIAS}

1 Equihua F, Salinas A, Nava E. Effect of aluminum content on austenite-ferrite transformation temperature in low carbon ( $\mathrm{Si}-\mathrm{Al}$ ) hot rolled GNO electrical steels. Revista de Metalurgia, 46. 2010; Enero-Febrero, 1:78-85.

2 Marra, KM. Estudo das Condições de Laminação a Morno de Acabamento de um Aço UBC. Proceedings of 18th Rolling Conference - IAS - 2010, Rosario, Argentina. 2010; 1:1-10.

3 Usiminas. Catálogo de Produtos Laminados a Frio. 2014 [acesso em 26 jul. 2014]; 1:22. Disponível em: http://usiminas.com/wp-content/uploads/2014/02/novo-laminadosfrio-v20-baixa.pdf

4 Yue S, Jonas JJ. The Three Critical Temperatures of Steel Rolling and Their Experimental Determination. Materials Forum, No.14. 1990; 245-252.

5 Gorni AA, Silva MRS, Silveira JHD. Laminação Ferrítica de Tiras a Quente. $41^{\circ}$ Seminário de Laminação - Processos e Produtos Laminados e Revestidos, Joinville (SC). 2004. 